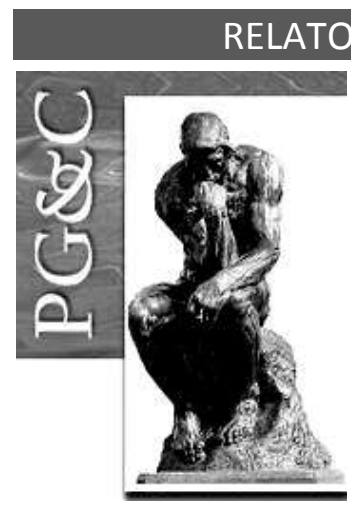

\title{
AVALIAÇÃO DA MATURIDADE DE GESTÃO DA INFORMAÇÃO E DO CONHECIMENTO: UM ESTUDO APLICADO EM TRÊS EDITORAS UNIVERSITÁRIAS FEDERAIS DO SUL DO BRASIL
}

\author{
Thaís Carmes Krüger \\ Mestre em Ciência da Informação pela Universidade Federal de Santa \\ Catarina, Brasil. Servidora Técnico-Administrativa em Educação da \\ Universidade Federal de Santa Catarina, Brasil. \\ E-mail: thaiskruger@gmail.com
}

Marli Dias de Souza Pinto

Doutora em Engenharia de Produção pela Universidade Federal de Santa Catarina. Brasil. Professora da Universidade Federal de Santa Catarina, Brasil. E-mail: marli.dias@ufsc.br

\begin{abstract}
Resumo
As adoções dos processos de Gestão do Conhecimento visam proporcionar melhorias na qualidade dos produtos e serviços prestados por uma organização, mediante a criação, disseminação e retenção de conhecimentos organizacionais que contribuam para sua competitividade. Quando mensurados em uma organização, esses processos permitem conhecer a capacidade e o nível de preparação dessa organização em utilizar de forma adequada seu capital intelectual, o que revela seu nível de maturidade em Gestão do Conhecimento. Assim, o objetivo geral deste estudo foi identificar o nível de maturidade em Gestão do Conhecimento, a partir da visão dos servidores de três editoras universitárias federais do sul do país, identificadas anonimamente como Editoras A, B e C, quando da análise dos resultados. $O$ instrumento para coleta de dados escolhido após uma revisão sistemática da literatura foi o questionário da Asian Productivity Organization. A análise da pontuação obtida a partir do referido questionário possibilitou classificar as editoras considerando seus pontos fortes e fracos, bem como concluir-se que as três editoras pesquisadas implementam práticas de gestão do conhecimento. Após a identificação do nível de maturidade, foram apresentadas propostas de melhoria para cada critério analisado.
\end{abstract}

Palavras-chave: Gestão do Conhecimento. Gestão da Informação. Maturidade em Gestão do Conhecimento. Editoras universitárias. Asian Productivity Organization (APO).

\section{ASSESSMENT OF INFORMATION AND KNOWLEDGE MANAGEMENT MATURITY: A STUDY APPLIED IN THREE FEDERAL UNIVERSITY PUBLISHER IN SOUTHERN BRAZIL}

\begin{abstract}
How the actions of the Knowledge Management processes aim to improve the quality of products and services provided by an organization, through the creation, dissemination and retention of organizational knowledge that contribute to its economy. When measured in an organization, these processes can know the capacity and level of preparedness of that organization to use the appropriate format of its intellectual capital, or what reveals its level of maturity in Knowledge Management. Thus, the general objective of this study was to identify the level of maturity in Knowledge Management, from the view of the servers, of three federal university publishers in the country, identified anonymously as Editora $A, B$ and $C$, when analyzing the results. The instrument for data collection chosen after a systematic review of the literature was the Asian Productivity Organization questionnaire. An analysis of the score selected from the aforementioned questionnaire allows classifying as editors considering their
\end{abstract}

Perspectivas em Gestão \& Conhecimento, João Pessoa, v. 10, n. 2, p. 120-142, maio/ago. 2020. DOI: http://dx.doi.org/10.21714/2236-417X2020v10n2p120

http://periodicos.ufpb.br/ojs2/index.php/pgc. ISSN: 2236-417X. Publicação sob Licença (cc) EY-NC-ND 
strengths and weaknesses, as well as concluding whether three surveyed editors implement knowledge management practices. After identifying the maturity level, improvements were applied to each analyzed criterion.

Keywords: Knowledge Management. Information Management. Maturity in Knowledge Management. University Publishers. Asian Productivity Organization (APO).

\section{INTRODUÇÃO}

A partir do momento em que Ikujiro Nonaka cunhou o termo Gestão do Conhecimento (GC) em um artigo de 1991 da Harvard Business Review, muitas empresas passaram a utilizálo. A GC vem sendo implementada em organizações públicas e privadas, com o intuito de propiciar melhorias na qualidade dos produtos e serviços prestados, bem como de tornar mais eficientes e eficazes os processos e serviços dependentes do conhecimento.

As organizações públicas como as instituições de ensino superior brasileiras, também têm que adotar Gestão do Conhecimento, especificamente, as Editoras universitárias, objeto do presente estudo. Deste modo, o objetivo focal aqui apresentado buscou: identificar o nível de maturidade em Gestão do Conhecimento a partir da visão dos servidores da Editora da Universidade Federal de Santa Catarina (UFSC), Editora da Universidade Federal do Paraná (UFPR) e Editora da Universidade Federal do Rio Grande do Sul (UFRGS).

As editoras universitárias brasileiras das instituições federais de ensino superior, objeto deste estudo, foram criadas, principalmente entre as décadas de 1960 e 1980 . Algumas nasceram junto com as universidades, outras surgiram a partir da experiência de imprensas ou gráficas universitárias que, com o passar dos anos de produção, criaram seus conselhos editoriais e formalizaram suas atividades com regimentos próprios (BUFREM, 2015).

As Instituições de Ensino Superior (IES), de maneira geral, buscam a qualidade em todos os seus processos, profissionalizando seus recursos humanos, investindo em tecnologias, trazendo para o dia a dia a GC, não só como conceito teórico, mas como instrumento para o desenvolvimento, a disseminação e a retenção do conhecimento (MAIA, 2003).

Nesse cenário, estão inseridas as editoras universitárias que, como parte dessas IES, precisa incorporar em suas práticas cotidianas e em seus projetos a gestão do conhecimento. A administração pública necessita de uma nova configuração, baseada em informação e conhecimento, onde aconteça interação entre pessoas, lideranças e tecnologias, ou seja, o efetivo gerenciamento do conhecimento para melhores resultados (BATISTA, 2012).

Sendo a GC uma área de pesquisa relativamente jovem, não existe consenso sobre como mensurá-la, nem sobre os benefícios de se adotar uma política voltada para a GC nas organizações. Para Araújo (2014), as primeiras reflexões nessa área se preocuparam com a natureza física da informação: reduzir o excesso, otimizar a circulação, identificar com precisão as necessárias e descartar as inúteis ou redundantes. Nesse sentido, os estudos foram transferidos para ambientes organizacionais, analisando o ambiente interno e o externo. Aos poucos, percebeu-se que a informação que mais interessa é aquela que ainda não está materializada, mas sim na mente das pessoas que pertencem às organizações. Assim, não basta gerir os recursos informacionais; se faz necessário, também, gerir o conhecimento.

Nesse contexto, a presente pesquisa, centrada em editoras, busca verificar como a GC pode viabilizar maneiras de aproveitar recursos que já existem dentro da organização, favorecendo o conhecimento geral e fazendo com que informações armazenadas de diversas maneiras sejam reunidas e utilizadas no processo de atividades diárias de todos os colaboradores.

Perspectivas em Gestão \& Conhecimento, João Pessoa, v. 10, n. 2, p. 120-142, maio/ago. 2020. 


\section{ASPECTOS TEÓRICOS CONCEITUAIS}

Nesta seção apresenta-se a sustentação teórica do estudo sobre Gestão do Conhecimento, Maturidade em Gestão do Conhecimento.

\subsection{GESTÃO DO CONHECIMENTO}

Desde a Grécia Antiga, os filósofos buscam entender o que é, afinal, o conhecimento. Platão introduziu o conceito de que conhecimento é uma "crença verdadeira justificada". Segundo essa definição, nossa crença na verdade de uma coisa não constitui nosso verdadeiro conhecimento dessa coisa, por isso existe uma chance, por menor que seja, de que nossa crença esteja errada. Portanto, a busca do conhecimento na filosofia ocidental é carregada de ceticismo (NONAKA; TAKEUCHI, 1997). O conhecimento surge de uma sequência lógica, em que a informação decorre de um conjunto de dados processados e o conhecimento, por sua vez, emerge de um conjunto de informações trabalhadas.

O conhecimento é atualmente um diferencial competitivo nos países e se consolida como fator-chave para que as organizações sobrevivam e se mantenham competitivas, portanto, precisa ser identificado e gerenciado (HERRERA, 2010; DAVILA et al., 2015).

Santos e Valentin (2014, p. 25) apontam que para a gestão do conhecimento se tornar uma realidade para a organização

\footnotetext{
é fundamental compreender que o conhecimento gerado por cada sujeito organizacional necessita ser compartilhado aos demais membros, fator que depende de ações sistemáticas voltadas a isso. Assim, é necessário que a organização aja como gestora do conhecimento gerado internamente, de modo a beneficiar sua própria capacidade de atuação.
}

A citação de Santos Valentim vai na direção dos estudos de Nonaka e Takeushi (1997), sinalizam que existem dois tipos de conhecimento, que se expandem em termos quantitativos e qualitativos: o conhecimento tácito e o explícito. Segundo os autores supracitados, essa classificação foi inicialmente abordada por Michael Polanyi em 1966 e, ao longo dos anos, foi enriquecida por outros autores.

O conhecimento explícito é o que pode ser articulado na linguagem formal, sistematizado e comunicado através de documentos, manuais, vídeos, entre outros veículos de comunicação, sendo, portanto, mais facilmente transmitido entre as pessoas. Já o conhecimento tácito, por sua vez, é difícil de ser articulado na linguagem formal, é pessoal e incorporado à experiência do indivíduo, compreendendo suas crenças pessoais, sistemas de valores, perspectivas, habilidades e emoções. Abrange, portanto, elementos subjetivos que não se encontram presentes no conhecimento explícito.

O conhecimento explícito é oriundo do conhecimento tácito e age como um guia que leva as pessoas à produção de novos conhecimentos sejam eles tácito ou explícito (GASPAR, 2010). O conhecimento tácito é subjetivo, ligado aos sentidos e ao contexto, além de altamente pessoal, dificultando sua formalização. Já o conhecimento explícito independe do contexto, podendo ser expresso e transmitido em forma de dados, recursos visuais, de maneira sistemática.

A partir das distinções apresentadas conceitualmente, o conhecimento tácito e o explícito não devem ser vistos como entidades separadas, mas mutuamente complementares (NONAKA; VON KROGH, 2009). Essa ideia fica evidente ao analisar-se a Espiral do Conhecimento, criada por Nonaka e Takeuchi (1997), que se constitui uma abordagem baseada na tradição intelectual e filosófica do Japão, que valoriza e integra os vários tipos de conhecimentos, esclarecendo que a inovação e a criação de novos conhecimentos 
organizacionais derivam da transformação ou conversão do conhecimento tácito em conhecimento explícito.

Segundo a Espiral do Conhecimento, o modo de socialização ocorre quando há o compartilhamento das experiências entre os indivíduos, por meio da mera observação e interação entre eles, sem necessariamente usar a linguagem. Deste modo, baseado nas experiências individuais e dos grupos envolvidos, transformando conhecimentos tácitos em novos conhecimentos tácitos. Já a externalização acontece quando há um processo de articulação do conhecimento tácito em conceitos explícitos por meio de metáforas, analogias, modelos, linguagem e reflexão do grupo. A combinação, por sua vez, é o modo como ocorre a criação de um novo conhecimento explícito, como ocorre no aperfeiçoamento de documentos, reuniões, bancos de informações, e até mesmo o ensino em um programa de pós-graduação. Em conclusão à espiral do conhecimento, na internalização há a incorporação do conhecimento explícito no conhecimento tácito, procedimento diretamente relacionado ao "aprender fazendo" (NONAKA; TAKEUCHI, 1997, p. 80).

A partir do argumento citado anteriormente, pode-se verificar que os autores enfatizam a criação contínua de novos conhecimentos, demonstrando que a proposta da GC está além da gestão daquilo que já existe, de maneira sistemática. Em uma perspectiva complementar, Lee e Yang (2000) definem a GC como uma coleção de processos que governam a criação e a disseminação do conhecimento com o intuito de alcançar os objetivos organizacionais.

Uriarte (2008) corrobora ao dizer que GC é a conversão do conhecimento tácito em conhecimento explícito e seu consequente compartilhamento com toda a organização. De maneira mais técnica, o autor conceitua GC como o processo a partir do qual a organização gera valor, por meio de seus ativos intelectuais e de conhecimento. Assim, a GC refere-se ao processo de identificar, adquirir, distribuir e reter os conhecimentos que são essenciais para a organização se manter eficiente, eficaz, efetiva e competitiva.

Independentemente do tipo de conhecimento mais latente dentro de uma organização, é notável a importância de se realizar a sua gestão. Gerir conhecimento, como qualquer outra forma clássica de gestão, significa planejar, organizar, coordenar e orientar o conhecimento dentro das organizações.

Spender (2001) ressalta que é importante que os gerentes examinem o conhecimento da mesma forma que consideram os modelos contábeis, administrativos e comerciais que adotam para os ativos tangíveis da organização. Gerentes que consideram a organização como um sistema que gera, dissemina, compartilha e aplica o conhecimento, adquirem condições para maximizar a atuação da organização e melhorar seu desempenho. Saber como lidar com os processos organizacionais e a criatividade individual e coletiva, tanto das organizações privadas quanto públicas, está tornando cada vez mais relevante o papel dos líderes diante das transformações e imprevisibilidade das situações do mundo atual.

Pode-se diferenciar, desse modo, a gestão do conhecimento em setores privados e públicos. As empresas privadas implementam a GC por estarem constantemente buscando sobreviver, seja para diferenciarem-se de outras ou para aumentar a produtividade e, consequentemente, os lucros. No setor público não existe essa preocupação, de modo que a GC pode ser incorporada com um foco maior na prestação dos serviços, atendimento ao cidadão, fornecimento das informações, compartilhamento do conhecimento, além da aprendizagem e inovação.

Para Batista (2012), a GC deve promover os princípios contemplados no Art. 37 da Constituição Federal, pois está relacionada a eles. Quais sejam: legalidade, impessoalidade, moralidade, publicidade e eficiência. Observa que a GC pode contribuir para que a administração pública atenda, por exemplo, ao princípio da impessoalidade, ou seja, tratar da mesma maneira todos os cidadãos (BRASIL, 1988).

Perspectivas em Gestão \& Conhecimento, João Pessoa, v. 10, n. 2, p. 120-142, maio/ago. 2020. 
A utilização de várias práticas de GC com a finalidade de garantir a concretização de um sólido arcabouço para a organização ressurge como uma grande vantagem competitiva no mundo moderno, na medida em que envolve pessoas, conhecimentos e processo de diferentes setores.

Comungando com esta ideia Costa, Gomes, Duarte e Valentin (2018) apontam que a literatura nacional e a internacional apresentam vários modelos de Gestão do conhecimento construídos por diversas etapas, processos ou dimensões, a maioria deles comuns, com destaque para pessoas, tecnologia e cultura organizacional.

A gestão do conhecimento, segundo Mattera (2014), oferece à organização um conjunto de práticas, metodologias e ferramentas para o aperfeiçoamento de sua gestão visando à excelência por meio da aplicação efetiva do conhecimento organizacional, o que contribui para a melhoria contínua e a inovação de diferentes processos, por exemplo: aquisição, criação, armazenamento, compartilhamento, utilização e reutilização do conhecimento em uma organização.

Castro (2002) salienta que a GC influencia na competitividade das organizações, pois viabiliza e torna executáveis os princípios de gestão que têm como finalidade atingir a excelência e a busca contínua por melhorias. A GC envolve gestão de pessoas, portanto podese afirmar que o conhecimento é encontrado também nas interações que existem entre os indivíduos, os grupos e a organização (DALKIR, 2005).

A Asian Productivity Organization (APO) destaca que o ponto de partida da GC é entender a visão, a missão, a direção e os objetivos da organização, com base nos elementos: pessoas (liderança), processos e tecnologia. Essa compreensão permite uma implementação de GC bem-sucedida (YOUNG, 2010).

Segundo Probst, Raub e Romhardt (2002), na sociedade do conhecimento para as organizações sobreviverem e competirem faz-se necessário um sistema de GC. Para contemplar essa necessidade, o próximo item apresenta a Maturidade em Gestão do Conhecimento.

\subsection{Maturidade em Gestão do Conhecimento}

A mensuração da gestão do conhecimento ganhou destaque nas publicações científicas e define níveis de maturidade representando o estágio em que a empresa está posicionada em relação à gestão de seus ativos intangíveis e, especialmente, em relação à GC.

Mesmo sem saber ao certo o que é a Gestão do Conhecimento, muitas organizações utilizam ferramentas relacionadas, por isso uma das primeiras ações é avaliar a GC para uma implantação eficaz (FREIRE et al., 2013). Uma forma de avaliação é com a utilização de modelos de maturidade.

Mensurar o grau de maturidade da gestão do conhecimento nas organizações se tornou uma prática amplamente adotada, mas muitas organizações ainda lutam para mensurar os ganhos que ela promete oferecer. O nível de maturidade em GC é uma escala de medida onde se pode avaliar a capacidade e o nível de preparação de uma organização em utilizar de forma adequada seus ativos intelectuais ou capital intelectual, isto é, os sujeitos que a compõem. Por capital intelectual entende-se o conjunto de ativos intangíveis representado pelo acervo de conhecimentos e geradores do diferencial competitivo, que agregam valor à organização (BATISTA, 2012).

Na revisão sistemática da literatura, efetivada para o presente estudo, recuperou-se os modelos de maturidade em gestão do conhecimento dos seguintes autores: (NONAKA; TAKEUCHI; 1997; INFOSYS 1999; PROBST; RAUB; ROMHARDT, 2002; KMMM SIEMENS, 2004); KRUGER; SNYMAN, 2007; CHONG; CHOY; WONG, 2009; PEE; KANKANHALLI, 2009; CHAWLA; JOSHI 2010; OSTERWALDER; PIGNEUR, 2011; BATISTA, 2012).

Perspectivas em Gestão \& Conhecimento, João Pessoa, v. 10, n. 2, p. 120-142, maio/ago. 2020. 
Na literatura comumente encontram-se modelos que contemplam processos de GC e fatores críticos de sucesso desenvolvidos para as organizações privadas.

O Modelo de Gestão do Conhecimento para a Gestão Pública Brasileira, elaborado por Batista (2012) atende as especificidades e necessidades do setor público, por este motivo este foi o modelo de maturidade nesse estudo. O instrumento para avaliação do nível de maturidade em GC é uma adaptação/tradução do modelo da APO e possui duas partes diretamente interessadas: o usuário, entendido como sujeito individualmente concebido, e a sociedade, vista como uma coletividade determinada ou não.

Em relação aos cidadãos, usuários do serviço público, a Gestão do Conhecimento volta-se a cumprir a finalidade atribuída à organização pública, ao realizar de forma otimizada os direitos constitucionalmente consagrados em favor dos indivíduos. A referida realização constitui o ponto central de todas as ações desenvolvidas no plano estratégico pela Gestão do Conhecimento junto às organizações públicas (BATISTA, 2012). O modelo é apresentado resumidamente na Figura 1:

Figura 1 - Modelo de Gestão do Conhecimento para a Administração Pública

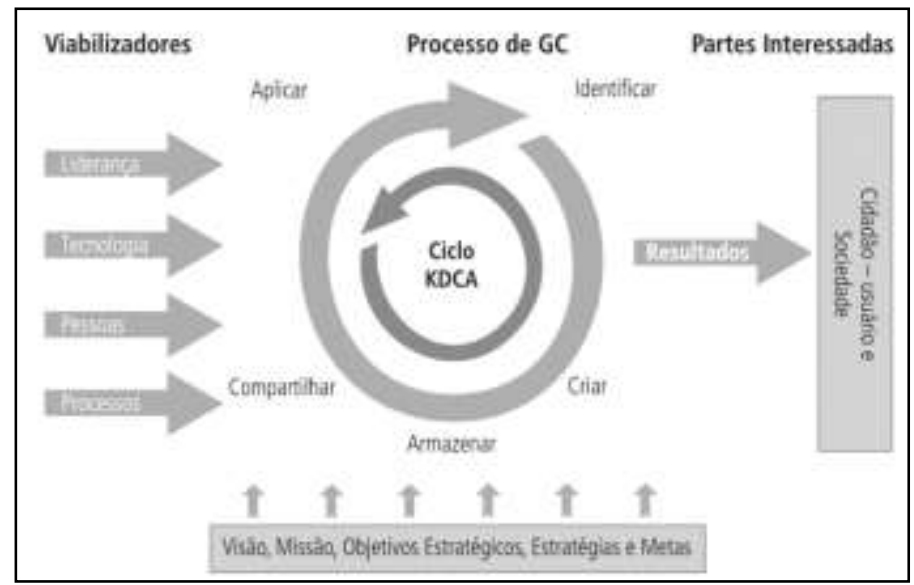

Fonte: Batista (2012, p. 52)

O modelo concebido por Batista (2012), apresentado na Figura 1, avalia os eixos: a) Direcionadores estratégicos: visão, missão, objetivos estratégicos, estratégias e metas, os quais ajudam a identificar a analisar as competências essenciais; b) Viabilizadores: liderança, tecnologia, pessoas e processos, que contribuem para entender até que pontos esses fatores estão presentes na organização; c) Processos de GC: identificar, criar, armazenar, compartilhar e aplicar conhecimento; d) Ciclo KDCA: auxilia na realização de um mapeamento inicial das práticas de GC existentes na organização, que podem ser disseminadas durante a implementação; e) Resultados esperados: medem a efetividade do processo de GC apoiado pelos fatores críticos de sucesso ou viabilizadores e fundamentados nos direcionadores estratégicos.

São sete os critérios de avaliação da Gestão do Conhecimento que integram o instrumento de Batista para mensurar o nível de maturidade em GC, conforme Figura 2: 
Figura 2 - Critérios de avaliação da GC

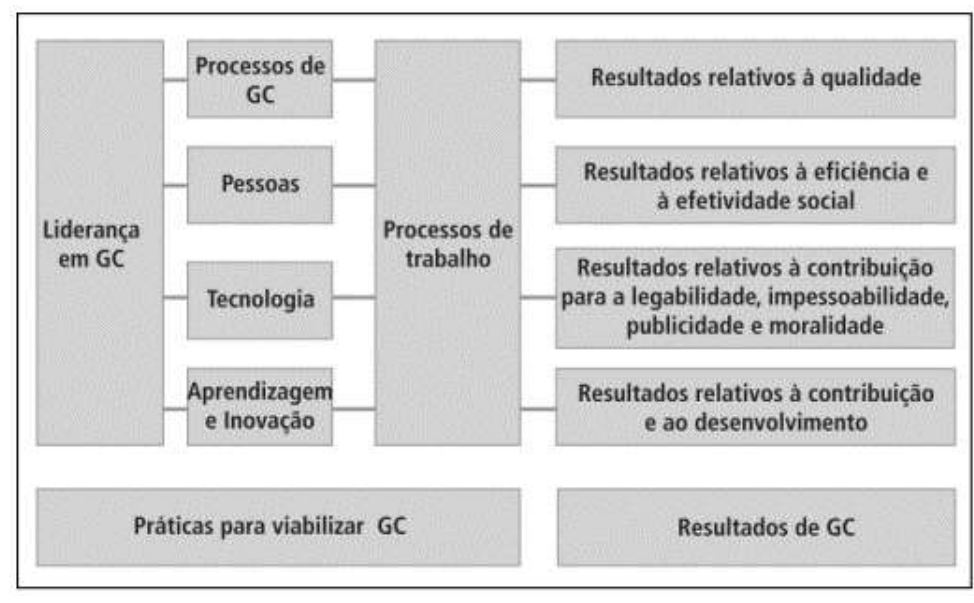

Fonte: Batista (2012, p. 93)

Além de ter sido escolhido pela pesquisadora para a formação de um modelo para a administração pública brasileira, o instrumento de coleta de dados utilizado por Batista (2012) é aquele concebido pela APO, traduzido por ele. São sete os critérios de avaliação da Gestão do Conhecimento que integram o instrumento de Batista para mensurar o grau de maturidade em GC, a saber: a) Liderança em Gestão do Conhecimento b) Processo c) Pessoas d) Tecnologia e) Processos de GC f) Aprendizagem e Inovação g) Resultados da GC, que apresenta-se em sequência.

a) Liderança

A liderança desempenha um papel fundamental para o sucesso da implementação da GC nas organizações públicas.

A responsabilidade da liderança se propõe: estabelecer a estrutura de governança e os arranjos organizacionais para formalizar as iniciativas de GC. Também, aloca recursos financeiros para viabilizar as iniciativas de GC e assegura a utilização da GC para melhorar processos, produtos e serviços.

Responde ainda, pela política de proteção do conhecimento (contemplando direitos autorais, patentes e segurança do conhecimento) e se envolve em instituir um sistema de reconhecimento e recompensa pela melhoria do desempenho, aprendizado individual e a criação do conhecimento e inovação.

Por fim, alta administração e as chefias intermediárias devem servir de exemplo à força de trabalho no que diz respeito a pôr em prática os valores de compartilhamento do conhecimento e de trabalho colaborativo (BATISTA, 2012).

Sinaliza ainda, o autor que a descontinuidade da administração é um fator negativo para a GC, fato que, geralmente ocorre na Administração pública, pela rotatividade de gestor, que em muitos casos não dão seguimento aos projetos anteriores bem-sucedidos.

\section{b) Processos}

Como conjunto de atividades que transformam insumos em produtos e serviços na organização por meio de pessoas que utilizam recursos entregues por fornecedores (BATISTA, 2012)

Os processos podem ser utilizados em benefício da gestão do conhecimento das seguintes formas:

Processes sistemáticos e modelados podem contribuir para aumentar a

Perspectivas em Gestão \& Conhecimento, João Pessoa, v. 10, n. 2, p. 120-142, maio/ago. 2020. 
eficiência, melhorar a qualidade e a efetividade social e contribuir para a legalidade, impessoalidade, publicidade e moralidade; Melhores práticas identificação e difusão de melhores práticas, sendo documentadas por meio de banco de dados, manuais ou diretrizes; Benchmarking interno e externo - prática relacionada à busca sistemática das melhores referências para comparação; Memória organizacional/lições aprendidas/banco de conhecimentos - indica o registro do conhecimento organizacional sobre processos, produtos, serviços e relacionamento com os cidadãos-usuários. Sistema de gestão por competências - indica a existência de uma estratégia de gestão baseada nas competências requeridas para o exercício das atividades de determinado posto de trabalho e a remuneração pelo conjunto de competências efetivamente exercidas; Banco de competências organizacionais - trata-se de um repositório de informações sobre a localização de conhecimentos na organização; Gestão do capital intelectual ou gestão dos ativos intangíveis - mapeamento dos ativos organizacionais. (BATISTA, 2012, p. 58).

Os processos de maneira geral possibilitam que os recursos disponíveis sejam utilizados de maneira adequada, a fim de obter o máximo proveito.

\section{c) Pessoas}

No desenvolvimento das organizações e as pessoas são fundamentais nos processos de GC. Para Batista (2012), as organizações públicas têm que investir em programas de capacitação e educação, bem como no desenvolvimento de carreiras, ajudando os servidores e gestores a identificar, criar, armazenar e aplicar o conhecimento. Desta, maneira possibilita contribuir para alcançar os objetivos e melhorar o desempenho institucional.

\section{d) Tecnologia}

Em relação à Tecnologia ela viabiliza e acelera os processos de GC. Essas práticas contribuem para a criação, o armazenamento, o compartilhamento e a aplicação do conhecimento. A tecnologia ajuda na gestão do conhecimento explícito mediante várias ferramentas, tais como: mecanismos de busca, repositórios de conhecimentos, intranets e extranets (BATISTA, 2012):

\section{e) Processos de GC}

Essas atividades de GC formam um processo integrado chamado no modelo de GC para a Administração pública e, as atividades são de: identificar, criar, armazenar, compartilhar e aplicar.

Para Batista (2012) as atividades são de: Identificar competências e lacunas para definir a estratégia para elaborar e implementar plano de GC; Criar, ou seja, eliminar as lacunas por meio da conversão do conhecimento e a criação de novos conhecimentos, que pode ocorrer em três níveis: individual, da equipe e organizacional; para preservação do conhecimento o armazenamento é fundamental e, este deve ser de fácil recuperação; Compartilhar promove a aprendizagem contínua e a inovação. Depende da confiança entre as pessoas e, por fim aplicar o conhecimento agrega valor apenas quando é aplicado nos processos de apoio e processos finalísticos, o que possibilita a utilização e reutilização do conhecimento da organização.

\section{f) Aprendizagem e Inovação}

A inovação como componente da relação entre conhecimento e aprendizagem em organizações, apresenta itens a seguir que merecem ser ressaltados: constantemente articula

Perspectivas em Gestão \& Conhecimento, João Pessoa, v. 10, n. 2, p. 120-142, maio/ago. 2020. 
e reforça a necessidade de aprendizagem e a inovação; Correr riscos como oportunidades de aprendizagem desde que isso não ocorra repetidamente; Formar equipes interfuncionais para resolver problemas ou lidar com situações preocupantes; possibilitar Autonomia dos membros da equipe, tendo suas ideias e contribuições valorizadas; ter disposição para usar novas ferramentas e métodos e, por fim, incentivar o trabalhar coletivo e o compartilhamento de informação.

g) Resultados de GC

Os resultados da GC podem ser divididos em: imediatos e finais. Os resultados imediatos são aprendizagem e inovação e, como consequência, o incremento da capacidade de realização individual, da equipe, da organização e da sociedade de identificar, criar, armazenar, compartilhar e aplicar conhecimento. Os resultados finais da GC decorrem dos imediatos e são: aumentar a eficiência, melhorar a qualidade e a efetividade social, contribuir para a legalidade, impessoalidade, moralidade e publicidade na administração pública e para o desenvolvimento brasileiro (BATISTA, 2012).

Com base na pontuação obtida, é possível identificar o nível de maturidade em GC que a organização se encontra. A Figura 3 apresenta os cinco níveis adotados por Batista (2012) para mensurar o nível de maturidade de GC em instituições públicas.

Figura 3 - Níveis de Maturidade em GC

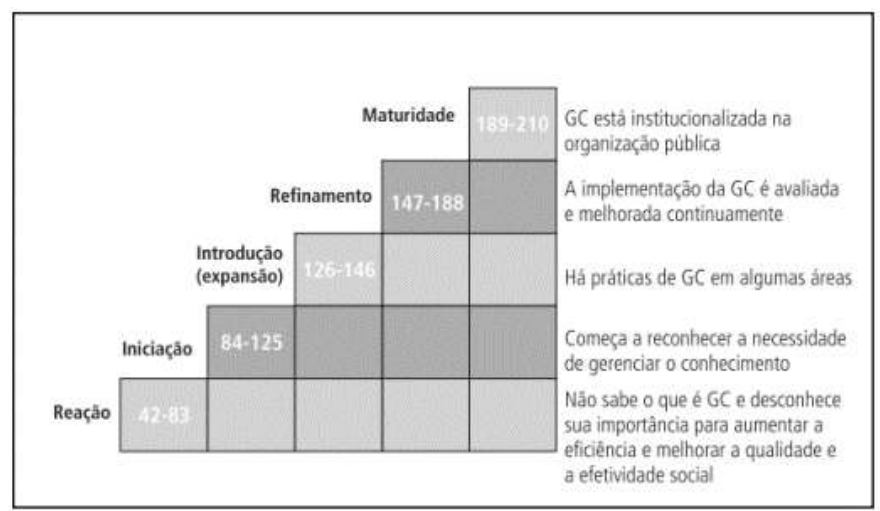

Fonte: APO (2009 apud BATISTA, 2012)

A Figura 3 apresenta o grau ou nível de maturidade em Gestão do Conhecimento, uma escala de medida em que se pode avaliar a capacidade e o nível de preparação de uma organização em utilizar de forma adequada seus ativos intelectuais ou capital intelectual. Por capital intelectual entende-se o conjunto de ativos intangíveis representado pelo acervo de conhecimentos e geradores do diferencial competitivo, que agregam valor à organização (BATISTA, 2012).

Ao utilizar se o Modelo de Maturidade de GC do Batista (2012) cada questão do questionário este poderia proporcionar uma pontuação entre 1 e 5 . Sendo 42 questões, o somatório do questionário varia, deste modo de 42 pontos e 210 pontos, sendo:

a) De 42 a 83 pontos = Reação: Não sabe o que é Gestão do Conhecimento e desconhece sua importância para aumentar a eficiência e melhorar a qualidade e efetividade social.

b) De 84 a 125 pontos = Iniciação: Começa a reconhecer a necessidade de gerenciar o conhecimento.

c) De 126 a 146 pontos = Introdução: Há práticas de Gestão do Conhecimento em algumas áreas.

Perspectivas em Gestão \& Conhecimento, João Pessoa, v. 10, n. 2, p. 120-142, maio/ago. 2020. 
d) De 147 a 188 pontos = Refinamento: A implementação da Gestão do Conhecimento é avaliada e melhorada continuamente.

e) De 189 a 210 pontos = Maturidade: Gestão do Conhecimento está institucionalizada na organização pública.

Para Kraemer e colaboradores (2017), o tema maturidade de GC é um campo fértil de pesquisa que oferece várias possibilidades. A carga excessiva depositada na tecnologia merece críticas, mas novos caminhos com foco em pessoas estão surgindo, precisando que mais estudos testem esses modelos.

A maturidade pode ser utilizada para avaliar diversas empresas ou setores de um país, mas ainda não existem comparações internacionais. E a investigação acerca das barreiras e facilitadores para as mudanças de níveis de maturidade ainda é um tema emergente.

\section{PERCURSOS METODOLÓGICOS}

Trata-se de uma pesquisa aplicada, quanto aos objetivos caracteriza-se como exploratório-descritiva e quanto aos procedimentos técnicos em pesquisa bibliográfica e documental.

Na pesquisa bibliográfica realizou-se uma revisão sistemática da literatura (RSL), sobre análise do grau de maturidade em gestão do conhecimento. Com os critérios de seleção buscou-se: de fontes acesso eletrônico (bases de dados, banco de teses e dissertações, anais de eventos) com abrangência interdisciplinar na Base de Dados em Ciência da Informação (BRAPCI), Biblioteca Digital Brasileira de Teses e Dissertações (BDTD), Library and Information Science Abstracts (LISA) e Scopus. As publicações deveriam ter o formato de estudo de caso, ser em língua inglesa ou portuguesa, com acesso aberto ao texto na íntegra, devendo apresentar procedimentos metodológicos.

A recuperação de informação foi efetuada por buscas utilizando a seguinte sequência: Bases de dados internacionais, utilizando as palavras-chave: knowledge management maturity, km maturity, maturity model for knowledge management, maturity model for $\mathrm{km}$, maturity model of knowledge management, maturity model of $\mathrm{km}$; Bases de dados nacionais, pelas palavras-chave: maturidade em gestão do conhecimento, maturidade em GC, modelo de maturidade em gestão do conhecimento e modelo de maturidade para gestão do conhecimento; Uso do operador booleano "OR" e Período cronológico: 2007-2017.

A Tabela 1 apresenta um resumo da revisão sistemática da literatura da RSL realizada:

Tabela 1 - Resumo da revisão sistemática da literatura

\begin{tabular}{l|c|c|c}
\hline $\begin{array}{c}\text { Bases de dados } \\
\text { pesquisadas }\end{array}$ & $\begin{array}{c}\text { Quantidade } \\
\text { recuperada }\end{array}$ & Quantidade utilizada & $\begin{array}{c}\text { Percentual quantidade } \\
\text { utilizada }\end{array}$ \\
\hline BRAPCI & 04 & 02 & $50 \%$ \\
\hline BDTD & 08 & 05 & $62 \%$ \\
\hline LISA & 65 & 07 & $11 \%$ \\
\hline SCOPUS & 32 & 07 & $\mathbf{2 2 \%}$ \\
\hline Total & $\mathbf{1 0 9}$ & $\mathbf{2 1}$ & $\mathbf{1 9 \%}$ \\
\hline
\end{tabular}

Fonte: Elaborado pelas autoras (2017).

Conforme Tabela 1 a seleção deu-se por meio da leitura dos títulos, resumos e palavras-chave, formando uma lista com as publicações relevantes. Do total de 109 (100\%) publicações, 21 (19\%) destas, estavam alinhados com o estudo e foram utilizadas, sete (30\%) são em português e 14 (70\%) em inglês. Verifica-se que a maioria 16 (76\%) das publicações são

Perspectivas em Gestão \& Conhecimento, João Pessoa, v. 10, n. 2, p. 120-142, maio/ago. 2020. 
recentes, compreendendo o período entre 2010 e 2017.

Trata-se ainda, de um estudo multicaso, por abranger três editoras de universidades federais, situadas na região sul do Brasil. Yin (1990, p. 52) afirma que a evidência obtida através do multicasos é "[...] mais determinante e o estudo como um todo é mais robusto".

O universo da pesquisa composto pela totalidade de 45 editoras de 63 universidades federais. Fizeram parte da amostra as Editoras da: Universidade Federal de Santa Catarina, Editora da Universidade Federal do Rio Grande do Sul e Editora da Universidade Federal do Paraná foram escolhidas por intencionalidade, uma vez que as três editoras situadas na região sul do Brasil teria maior facilidade de efetuar a pesquisa e, também porque essas Editoras têm quantidades equivalente de servidores

Os 44 servidores foram os sujeitos pesquisados, distribuídos da seguinte maneira: Editora A, 14; Editora B, 15 e; Editora C, 15.

Como instrumento de coleta de dados utilizou-se o questionário citado da APO, composto por 42 questões fechadas sobre Maturidade na Gestão do conhecimento, divididas entre sete critérios de GC. Em cada uma dessas dimensões o respondente deve identificar pontos fortes e fracos (questões abertas). Para traçar o perfil foram incluídas, ainda, sete perguntas fechadas.

É importante ressaltar que ao receber o questionário o respondente poderia aceitar ou não os Termos do Consentimento Livre e Esclarecido (TCLE).

O tratamento dos dados do questionário teve uma abordagem quantitativa/qualitativa, pela própria característica da pesquisa. As respostas foram tratadas de forma qualitativa, considerando as pontes fortes e pontos fracos de cada uma das dimensões. Foi utilizada a análise de conteúdo de Bardin (2016), que prevê as fases de préanálise, exploração do material e tratamento dos resultados - a inferência e a interpretação.

As questões que ajudaram a definir o nível de maturidade em gestão do conhecimento foram analisadas de maneira quantitativa, permitindo aplicação de métodos estatísticos e até generalizações (CUNHA; AMARAL; DANTAS, 2015).

\section{RESULTADOS}

O questionário aplicado era composto pela: Parte I - Perfil dos Pesquisados, com 7 perguntas e Parte II - Visão dos servidores a partir do instrumento da APO - com 42 proposições, divididas igualmente entre 6 dimensões ou critérios, que são: liderança, processos, pessoas, tecnologia, processos de conhecimento, aprendizagem e inovação e resultados de gestão do conhecimento. Dentro de cada um dos 7 critérios, o participante da pesquisa poderia discorrer sobre pontos fortes e pontos fracos.

\subsection{Perfil dos pesquisados} feminino.

A maioria dos respondentes (65\%) das três editoras se identificou como gênero

A faixa etária verifica-se um equilíbrio no cômputo geral: participantes entre 34 e 41 anos, 42 e 49 anos e 50 anos ou mais representaram (30\%) cada um; de 26 a 33 anos somam (10\%). Na Editora B há um equilíbrio de 34 a 41 anos (38\%), 42 a 49 anos e 50 anos ou mais, ambos com (31\%) cada. A Editora $C$ apresentou respostas apenas de participantes de 42 a 49 anos (50\%) e 50 anos ou mais (50\%). Novamente a Editora A se difere das demais, tendo respondentes mais jovens, de 26 a 33 anos, representando (67\%) dos respondentes, e (33\%) foram de 34 a 41 anos.

Quanto a titulação todos os respondentes possuem no mínimo graduação completa, sendo a única formação para $10 \%$ deles. O mestrado concluído é a formação mais comum 
representando $30 \%$ do total. Em seguida aparecem os respondentes com doutorado concluído, empatado com especialização concluída 20\%. Mestrado em andamento representou $15 \%$, graduação concluída $10 \%$ e especialização em andamento (5\%). Interessante observar, portanto, o alto nível de qualificação encontrado nas três Editoras estudadas.

Quanto aos cargos na Editora A: Programador Visual, com (67\%) e Contador, com (33\%). Na Editora B, os cargos de Assistente em Administração e Revisor representaram (23\%), seguidos de Técnico em Assuntos Educacionais com (15\%) e Administrador, Auxiliar em Administração, Docente, Programador Visual e Técnico em Contabilidade, com (8\%) cada um. $\mathrm{Na}$ Editora $\mathrm{C}$ os cargos estão divididos igualmente entre Assistente em Administração, Docente, Revisor e Técnico de Laboratório, todos com $25 \%$ cada; $55 \%$ dos respondentes não ocupam cargos de direção ou funções gratificadas. Todos os participantes da Editora A responderam que não ocupam cargo de chefia. Já na Editora $C$, todos responderam que ocupam. Na Editora B apareceram respostas com e sem chefia/cargos de direção: $61 \%$ não ocupam e $39 \%$ sim, distribuídos entre CD-4, FG-1, FG-2 e FG-4.

Quanto ao tempo de serviço mais de $45 \%$ atuam nas editoras há mais de 5 anos. Na Editora C, por exemplo, esse tempo de serviço apareceu para $75 \%$ dos respondentes. $\mathrm{Na}$ Editora C, representou 46\%, seguida por (30\% daqueles que possuem apenas entre 1 e 2 anos de Editora. Já na Editora C, a distribuição das respostas ficou entre 1 e 6 meses, 2 a 3 anos e 3 a 4 anos, todas com $33 \%$.

A partir do perfil dos pesquisados infere-se que, de maneira geral, possuem considerável grau de escolaridade e, com tempo de serviço significativo nas Editoras, o que contribuiu responder o questionário, seja pela complexidade possivelmente encontrada nas questões, ou pelo conhecimento mais profundo do funcionamento dessas unidades de informação.

\subsection{Resultado do nível de maturidade em GC na visão dos servidores das três editoras estudadas}

A partir do somatório dos sete critérios analisados, identificou-se o nível de maturidade em gestão do conhecimento na visão dos servidores das Editoras A, B e C, apresentado na Tabela 2 a seguir:

Tabela 2 - Grau de maturidade em Gestão do Conhecimento das três Editoras

\begin{tabular}{l|c|c|c}
\multirow{2}{*}{ Critérios } & \multicolumn{3}{|c}{ Pontuação por critério } \\
\cline { 2 - 4 } & A & B & C \\
\hline 1.0 Liderança & 19,33 & 14,46 & 18,75 \\
\hline 2.0 Pessoas & 22,33 & 16,85 & 21,25 \\
\hline 3.0 Processos & 17,33 & 14,46 & 18,50 \\
\hline 4.0 Tecnologia & 26,00 & 22,31 & 24,50 \\
\hline 5.0 Processos de Conhecimento & 19,00 & 14,77 & 19,25 \\
\hline 6.0 Aprendizagem e Inovação & 23,33 & 16,92 & 17,50 \\
\hline 7.0 Resultados de GC & 14,00 & 10,62 & 11,25 \\
\hline Totalização & 141 & 110 & 131 \\
\hline Maturidade em Gestão do Conhecimento & $\begin{array}{c}\text { Introdução } \\
\text { (expansão) }\end{array}$ & Iniciação & $\begin{array}{l}\text { Introdução } \\
\text { (expansão) }\end{array}$
\end{tabular}

Fonte: Dados da pesquisa (2018)

A partir do estudo de Batista (2012) as Editoras A e C obtiveram pontuação 141 e 131, respectivamente. Ambas se encontram no nível "Introdução/expansão", ou seja, ocorrem práticas de gestão do conhecimento em algumas áreas. Na Editora A a pontuação atingiu 110, 
o que resulta no nível "Iniciação", quando começa a reconhecer a necessidade de gerenciar o conhecimento.

O Gráfico 1 permite uma visão geral das três editoras em relação aos níveis estabelecidos pelo modelo da APO.

Gráfico 1 - Grau de maturidade em Gestão do Conhecimento

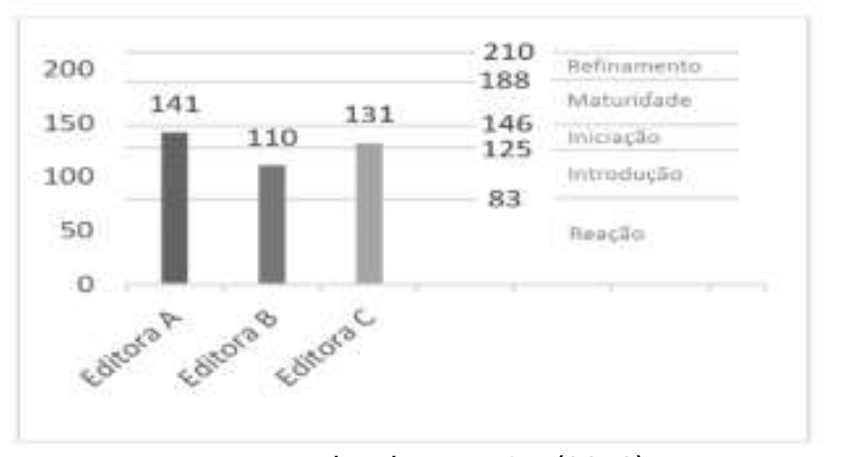

Fonte: Dados da pesquisa (2018)

Conforme Gráfico 1 destaca-se, apesar de ter obtido uma pontuação menor em relação às outras duas Editoras, os pontos fortes destacados fazem crer que a Editora $A$ também está no nível Introdução, pois há algumas iniciativas de GC colocadas em prática. Possivelmente, o fato de estar passando por uma reestruturação tenha tornado os participantes da pesquisa mais críticos na avaliação dos questionamentos.

4.2.1 Resultados dos pontos fortes e pontos fracos apresentados pelos servidores das três Editoras

Nesta seção apresenta-se resultados de cada um dos 7 critérios em que o servidor participante da pesquisa poderia discorrer sobre pontos fortes e pontos fracos, para tanto, foi reunido por similaridades e, para cada fragilidade sinalizada, elaborou-se Quadros com as proposições de melhoria a partir do que postula Batista (2012) e são apresentados a seguir.

\subsubsection{Critério Liderança}

Os respondentes da Editora $A$ foram abrangentes nas respostas e sinalizaram potencialidades na organização, planejamento, eficiência, responsabilização e incentivo ao aprendizado. Por outro lado, como oportunidade de melhoria, apareceu o fato de falta de incentivo ao aprendizado. Foi indicado também que alguns ocupantes de cargos de chefia não possuem as características esperadas de um líder.

$\mathrm{Na}$ Editora B, os participantes da pesquisa foram mais específicos e trouxeram como potencialidades características importantes de um líder, como empenho, perseverança, resiliência, motivação e organização. Como pontos fracos sinalizaram a comunicação, o excesso de centralização, controle e exigências, além da falta de incentivos, sejam eles elogios ou apoio para aperfeiçoamento.

$\mathrm{Na}$ Editora C a comunicação aparece como ponto forte. Estão incluídos também a promoção da união da equipe, criação de projetos inovadores, diálogo, eficiência, eficácia, comprometimento e objetividade. Como pontos fracos foram diagnosticados o não cumprimento de prazos internos, a falta de recursos humanos e de planejamento 
Quadro 1 - Critério Liderança: proposição de melhorias

\begin{tabular}{|c|c|c|c|}
\hline \multicolumn{4}{|c|}{ CRITÉRIO 1.0 - LIDERANÇA } \\
\hline Editora & Propostas & Responsáveis & Prazo \\
\hline \multirow{2}{*}{ Editora A } & Capacitar os líderes/ocupantes de chefia & Direção & 3 meses \\
\hline & Incentivar o compartilhamento de conhecimento & Direção e Chefias & 1 mês \\
\hline \multirow{2}{*}{ Editora B } & Capacitar os líderes/ocupantes de chefia & Direção & 3 meses \\
\hline & Elaborar um plano de comunicação & Direção e Chefias & 2 meses \\
\hline \multirow[b]{2}{*}{ Editora C } & Elaborar planejamento estratégico e alinhá-lo à GC & Direção e Chefias & 4 meses \\
\hline & $\begin{array}{l}\text { Servir de exemplo, para o trabalho colaborativo e o } \\
\text { cumprimento de prazos. }\end{array}$ & Direção e Chefias & 1 mês \\
\hline \multirow{3}{*}{ Todas } & Alocar recursos financeiros para a GC & Direção & 6 meses \\
\hline & Instituir uma política de reconhecimento e recompensa & Direção & 4 meses \\
\hline & $\begin{array}{l}\text { Estabelecer arranjos organizacionais que favoreçam as } \\
\text { iniciativas de GC }\end{array}$ & Direção & 6 meses \\
\hline
\end{tabular}

Fonte: Elaborado pelas autoras (2018)

No Quadro 1 foram apresentadas propostas para a melhoria da Gestão do Conhecimento no critério 1.0 - Liderança. Os responsáveis pela aplicação das propostas são as chefias, tendo em vista seu papel fundamental.

\subsubsection{Critério processos}

Para os servidores da Editora A apontam preocupação constantemente com os processos, buscando melhorá-los de forma eficiente e eficaz, com o foco voltado para a sociedade, também apontaram a possibilidade de sensibilizar os servidores quanto ao seu papel social, bem como a definição dos processos e hierarquia por meio de fluxogramas e organogramas.

Na Editora B sinalizaram que a definição dos processos e organização interna é recente. Algumas conquistas já foram alcançadas, como por exemplo, a reorganização da reserva técnica e a implantação de manuais no setor financeiro. Como ponto fraco foi apontado novamente à comunicação falha. Ademais, a descontinuidade dos processos causada possivelmente pela equipe pequena e rotatividade de bolsistas. Como o processo de reorganização é recente, apontou-se também a indefinição das atribuições e responsáveis, ausência de manuais e a desintegração dos setores.

$\mathrm{Na}$ Editora C, a adoção do Sistema Eletrônico de Informações (SEI) foi elencada como facilitador da agilidade e transparência dos processos. Por outro lado, o treinamento inicial do sistema foi insuficiente. Também foi citada pela EC a qualificação da equipe, bem como seu comprometimento. Ocorrem à revisão das práticas para melhoria dos processos, que são realizados com qualidade, pontualidade, transparência e ótimo desempenho. A falta de um planejamento anual que preveja os fatores de risco, bem como a falta de servidores foram às oportunidades de melhoria apontadas.

Quadro 2 - Critério Processos: proposição de melhorias para processos

\begin{tabular}{|c|c|c|c|}
\hline \multicolumn{4}{|c|}{ CRITÉRIO 2.0 - PROCESSOS } \\
\hline Editora & Propostas & Responsáveis & Prazo \\
\hline \multirow{3}{*}{ Editora A } & $\begin{array}{l}\text { Definir competências essenciais e alinhá-las à sua missão } \\
\text { e aos seus objetivos }\end{array}$ & Direção & 6 meses \\
\hline & Sensibilizar equipe sobre papel social do seu trabalho & Direção e chefias & 1 mês \\
\hline & Mapear funções/criar organogramas e fluxogramas & Chefias e equipe & 3 meses \\
\hline Editora B & Criação de manuais de procedimentos & Equipe & 4 meses \\
\hline
\end{tabular}

Perspectivas em Gestão \& Conhecimento, João Pessoa, v. 10, n. 2, p. 120-142, maio/ago. 2020. 


\begin{tabular}{|l|l|c|c|}
\hline \multirow{2}{*}{ Editora C } & Integração dos setores & \multicolumn{1}{|c|}{ Todos } & 3 meses \\
\cline { 2 - 4 } & $\begin{array}{l}\text { Realização de planejamento anual prevendo situações de } \\
\text { crise }\end{array}$ & $\begin{array}{l}\text { Mapear e otimizar os processoso e chefias } \\
\text { de pessoal }\end{array}$ & 6 meses \\
\hline \multirow{2}{*}{ Todas } & $\begin{array}{l}\text { Criação de um sistema próprio para gerenciamento de } \\
\text { crises }\end{array}$ & Equipe & 3 meses \\
\cline { 2 - 4 } & Sistematizar e modelar processos & \multicolumn{1}{|c|}{ Todos } & 4 meses \\
\hline
\end{tabular}

Fonte: Elaborado pelas autoras (2018)

O Quadro 2 levou em consideração as oportunidades de melhorias apresentadas pelos participantes da pesquisa bem como aquelas encontradas na literatura. A distribuição das atribuições dos responsáveis pelos processos ficou entre todos os servidores das Editoras.

\subsubsection{Critério pessoas}

Os servidores que responderam o questionário da Editora $\mathrm{A}$ consideram que existe sinergia, responsabilidade, eficiência entre as pessoas. Há abertura para a aprendizagem, troca de conhecimentos e trabalho em equipes multidisciplinares, mas sinalizam que não há iniciativas em gestão do conhecimento. Existe oportunidade para os servidores realizarem capacitações pontuais, carecendo ainda de autorização das chefias imediatas.

Para os servidores da Editora B, foram inseridas diversas características da equipe, tais como: competência, comprometimento, abertura para o diálogo, experiência, solidariedade, conhecimento, criatividade, cooperação e inovação. Relatam que falta de integração e de visão sistêmica, desconhecimento e/ou não aplicabilidade das legislações referentes ao incentivo de desenvolvimento do servidor. A comunicação interna deficiente foi novamente apontada desse quesito.

Por fim, na Editora C os servidores apontaram como pontos fortes a boa vontade da equipe, compartilhamento de conhecimento, alta qualificação dos profissionais (novamente), comprometimento, eficácia, eficiência, confiança, qualidade e participação. O principal ponto fraco apontado foi a equipe reduzida para realização das atividades. No Quadro 3 apresentamse as proposições de melhorias:

Quadro 3 - Critério Pessoas: proposição de melhorias

\begin{tabular}{|c|c|c|c|}
\hline \multicolumn{4}{|c|}{ CRITÉRIO 3.0 - PESSOAS } \\
\hline Editora & Propostas & Responsáveis & Prazo \\
\hline \multirow[t]{2}{*}{ Editora A } & $\begin{array}{l}\text { Disseminar informações de maneira sistemática sobre os } \\
\text { benefícios, a política, a estratégia, o modelo, o plano e as } \\
\text { ferramentas de GC }\end{array}$ & Todos & 6 meses \\
\hline & Prover iniciativas de GC & Direção & 1 mês \\
\hline \multirow[t]{2}{*}{ Editora B } & $\begin{array}{l}\text { Disseminar informações de maneira sistemática sobre os } \\
\text { benefícios, a política, a estratégia, o modelo, o plano e as } \\
\text { ferramentas de GC }\end{array}$ & Todos & 6 meses \\
\hline & $\begin{array}{l}\text { Criação de processo formal de aprendizagem } \\
\text { organizacional e compartilhamento de conhecimento }\end{array}$ & $\begin{array}{l}\text { Direção e } \\
\text { chefias }\end{array}$ & 4 meses \\
\hline Editora C & $\begin{array}{l}\text { Criação de processo formal de aprendizagem } \\
\text { organizacional e compartilhamento de conhecimento, } \\
\text { tendo em vista a falta de pessoal }\end{array}$ & $\begin{array}{l}\text { Direção e } \\
\text { chefias }\end{array}$ & 4 meses \\
\hline \multirow[b]{2}{*}{ Todas } & Formalizar processos de mentoring, coaching e tutoring & Direção & 6 meses \\
\hline & $\begin{array}{l}\text { Criação de bancos de competências organizacionais e } \\
\text { individuais }\end{array}$ & Todos & 4 meses \\
\hline
\end{tabular}

Fonte: Elaborado pelas autoras (2018) 
O Quadro 3 apresentou propostas para a melhoria da GC por meio do critério Pessoas.

\subsubsection{Critério tecnologia}

A Editora A compreende a tecnologia como o caminho para a rapidez e a comunicação. Considera que a intranet e o e-mail são utilizados como fonte de comunicação. Em resumo, que a Editora dispõe de tecnologia para desempenhar suas funções. Por outro lado, acreditam que a tecnologia poderia ser utilizada para acompanhamento dos processos, pois atualmente utilizam apenas com a finalidade operacional. Ponderam que para fins de Gestão de Conhecimento, não é utilizada (pelo menos não de maneira direta).

Na Editora B foram elencadas a importância da Tecnologia, as pastas Compartilhadas, a página da Editora, o software gerencial (Versa), a infraestrutura básica adequada e o apoio do setor de TI da Universidade. Já como oportunidades de melhoria, várias vezes surgiu como resposta à necessidade de um técnico especializado lotado na Editora, atendendo suas especificidades.

Sobre as pastas compartilhadas, apontam que nem todas estão acessíveis a todos e que não há padronização de organização do conteúdo. Sobre o Versa (sistema para gerenciamento comercial, administrativo e financeiro) apontaram que sua subutilização ou uso indevido dificultam os processos. O excesso de dependência da tecnologia também foi considerado um problema, tendo em vista que se há problemas na internet e/ou energia elétrica, há dificuldade em trabalhar.

A Editora $\mathrm{C}$ informa que os canais de comunicação parecem adequados e ativos, que a tecnologia é adequada para os processos e que possibilita a comunicação eficiente, como também permite a execução dos trabalhos com eficácia. Pondera as dificuldades de ser uma Editora Federal, o que implica em maior burocracia para renovação/manutenção/aquisição de softwares e equipamentos. Além disso, sugere uma fiscalização por meio eletrônico sobre crimes como plágio e fraudes em relação às publicações da editora.

Quadro 4-Critério Tecnologia: proposição de melhorias

\begin{tabular}{|l|l|c|c|}
\hline \multicolumn{3}{|c|}{ CRITÉRIO 4.0-TECNOLOGIA } & \multicolumn{1}{|c|}{ Propostas } \\
\hline Editora & \multicolumn{1}{|c|}{ Responsáveis } & Prazo \\
\hline \multirow{2}{*}{ Editora A } & $\begin{array}{l}\text { Ajudar na gestão do conhecimento explícito: mecanismos de } \\
\text { buscas, repositórios, intranets e extranets }\end{array}$ & Todos & 1 mês \\
\hline \multirow{2}{*}{ Editora B } & Criar padrão para organização das pastas compartilhadas & Chefias & 2 meses \\
\cline { 2 - 4 } & $\begin{array}{l}\text { Negociar com a TI da Universidade a disponibilização de um } \\
\text { técnico que possa atender as especificidades da Editora }\end{array}$ & Direção & 8 meses \\
\hline \multirow{2}{*}{ Editora C } & $\begin{array}{l}\text { Utilizar a tecnologia para identificar fraudes e plágio nas obras } \\
\text { submetidas }\end{array}$ & Equipe & 6 meses \\
\hline \multirow{2}{*}{ Todas } & $\begin{array}{l}\text { Utilizar tecnologia para apoiar a transferência de conhecimento } \\
\text { e o compartilhamento da informação }\end{array}$ & Todos & 1 mês \\
\hline
\end{tabular}

Fonte: Elaborado pelas autoras (2018)

O Quadro 4 apresenta as propostas para a Tecnologia, que foi o critério mais bem avaliado nas três Editoras pesquisadas.

\subsubsection{Critério Processos de Conhecimento}

A Editora A considera que o conhecimento dos trabalhadores que saem é retido e compartilhado e que há uma preocupação com o benchmarking e aprimoramento da qualidade. Todavia, não há processo formalizado de promoção do conhecimento.

Perspectivas em Gestão \& Conhecimento, João Pessoa, v. 10, n. 2, p. 120-142, maio/ago. 2020. 
Na Editora B, também ocorre o benchmarking, ou seja, troca de experiências entre Editoras. Como está acontecendo um processo de reestruturação, consideram que as rotinas precisam ser amadurecidas e assimiladas, entre outros pontos positivos. Quanto às oportunidades de melhoria, ponderam que o trabalho de reorganização deve ser balanceado com a dinâmica do trabalho, os perfis e a finalidade de uma editora universitária, e que há certa resistência às mudanças. Também que há ausência de registro formal dos processos e desconhecimento das atividades de outros setores ou servidores.

A Editora $C$ também apontou que o benchmarking é bem utilizado e que há uma busca constante por inovação. Salientou que como parte do processo de conhecimento, os grupos de áreas específicas se conversam e transmitem seus conhecimentos e dúvidas e, posteriormente, essas questões são colocadas em reuniões que envolvam outras áreas. Como pontos fracos apareceram, novamente, a falta de servidores e as limitações orçamentárias. Mostrou também que o mapa de conhecimentos não atinge a editora como um todo, pois é processado em cada setor individualmente e que seria necessário conhecer as experiências de outras editoras (em contraponto com o benchmarking apresentado como ponto forte).

Quadro 5 - Critério Processos de GC: proposição de melhorias

\begin{tabular}{|c|c|c|c|}
\hline \multicolumn{4}{|c|}{ CRITÉRIO 5.0 - PROCESSOS DE GC } \\
\hline Editora & Propostas & Responsáveis & Prazo \\
\hline \multirow[t]{2}{*}{ Editora A } & $\begin{array}{l}\text { Criar processos sistemáticos de identificação, } \\
\text { criação, armazenamento, compartilhamento e } \\
\text { aplicação do conhecimento }\end{array}$ & Chefias e equipe & 6 meses \\
\hline & $\begin{array}{l}\text { Formalizar processo de promoção do } \\
\text { conhecimento }\end{array}$ & Direção e chefias & 4 meses \\
\hline \multirow[t]{2}{*}{ Editora B } & $\begin{array}{l}\text { Criar procedimento para reter conhecimentos } \\
\text { de servidores que se aposentam }\end{array}$ & Direção e chefias & 1 mês \\
\hline & Criar registros formais de processos & Chefias & 4 meses \\
\hline Editora C & $\begin{array}{l}\text { Realizar atividades de benchmarking para } \\
\text { melhorar o desempenho da Editora e criar } \\
\text { conhecimento }\end{array}$ & Direção e chefias & 6 meses \\
\hline Todas & $\begin{array}{l}\text { Criar mapa de conhecimento e distribuir os } \\
\text { ativos ou recursos de conhecimento por toda a } \\
\text { Editora }\end{array}$ & Direção e chefias & 6 meses \\
\hline
\end{tabular}

Fonte: Elaborado pelas autoras (2018)

O Quadro 5 apresenta as propostas de melhorias para o critério 5.0 - Processos de GC.

\subsubsection{Critério Aprendizagem e Inovação}

Os integrantes da Editora A consideram que existe apoio para a troca de ideias e trabalho entre equipes, havendo ambiente propício para mudança, sinergia, aprendizagem, inovação e união. Como pontos negativos mencionaram a falta de critério para sansão a falhas e erros e o pouco incentivo à capacitação.

Os servidores da Editora B declaram que individualmente os trabalhadores estão dispostos a estudar, aprender e compartilhar. As chefias valorizam a aprendizagem e a inovação. Em relação à Universidade, alegam que são oferecidos diversos cursos e o conhecimento de ponta. Como pontos a serem desenvolvidos, alegam que não há incentivo financeiro, nem permissão para os afastamentos para formação e as chefias não recebem autonomia dos superiores hierárquicos. Mencionam também a falta de tempo para 0 intercâmbio de conhecimentos.

Já na Editora C, avaliam que a troca de experiências entre os funcionários mais antigos

Perspectivas em Gestão \& Conhecimento, João Pessoa, v. 10, n. 2, p. 120-142, maio/ago. 2020. 
e os mais novos é valorizada, além de haver o compartilhamento de informações e comprometimento e responsabilidade em assumir situações de risco. Como pontos fracos creem que nem sempre as pessoas aprendem com os erros e tanto a aprendizagem quanto a inovação são prejudicadas por falhas na comunicação.

Quadro 6 - Critério Aprendizagem e inovação: proposição de melhorias

\begin{tabular}{|c|c|c|c|}
\hline \multicolumn{4}{|c|}{ CRITÉRIO 6.0 - APRENDIZAGEM E INOVAÇÃO } \\
\hline Editora & Propostas & $\begin{array}{c}\text { Responsávei } \\
\text { s }\end{array}$ & Prazo \\
\hline Editora A & $\begin{array}{l}\text { Articular e reforçar continuamente como valores a } \\
\text { aprendizagem e a inovação }\end{array}$ & $\begin{array}{l}\text { Direção e } \\
\text { chefias }\end{array}$ & 1 mês \\
\hline \multirow{2}{*}{ Editora B } & $\begin{array}{l}\text { Formar equipes interfuncionais para resolver problemas ou } \\
\text { lidar com situações preocupantes }\end{array}$ & Todos & 3 meses \\
\hline & $\begin{array}{l}\text { Conceder autonomia aos subordinados, valorizando ideias e } \\
\text { contribuições }\end{array}$ & $\begin{array}{l}\text { Direção e } \\
\text { chefias }\end{array}$ & 1 mês \\
\hline \multirow{2}{*}{ Editora C } & $\begin{array}{l}\text { Formar equipes interfuncionais para resolver problemas ou } \\
\text { lidar com situações preocupantes }\end{array}$ & Todos & 3 meses \\
\hline & $\begin{array}{l}\text { Focar na comunicação para melhorar a aprendizagem e a } \\
\text { inovação }\end{array}$ & Todos & 3 meses \\
\hline Todas & $\begin{array}{l}\text { Assumir riscos como oportunidades de aprendizagem, } \\
\text { aprendendo com os erros }\end{array}$ & $\begin{array}{l}\text { Direção e } \\
\text { chefias }\end{array}$ & 3 meses \\
\hline
\end{tabular}

Fonte: Elaborado pelas autoras (2018)

O Quadro 6 apresenta os critérios de aprendizagem e inovação com proposições de melhorias após as fragilidades apontadas pelos servidores.

\subsubsection{Critério Resultados de GC}

Os servidores da Editora $A$ apontam que não existe um plano de gestão de conhecimento na Editora, dificultando listar pontos fortes. Há iniciativas isoladas, mas sem alinhamento ao planejamento da Editora. Consideram que há uma margem para a implantação de políticas de gestão do conhecimento.

A Editora B se posiciona da mesma forma, entendendo a importância da gestão do conhecimento. Listou como indicadores de qualidade: a variedade do catálogo, a qualidade da produção e revisão, a comercialização das obras, além de outros indicadores a partir do planejamento estratégico. Entendem que a implantação da livraria virtual permitiu a ampliação das vendas e a divulgação do catálogo. A participação constante em feiras e em eventos proporciona a venda, a divulgação e reconhecimento. Como aspectos negativos, cita a falta de recursos, sejam eles financeiros ou de pessoal.

$\mathrm{Na}$ Editora C consideram as tentativas de inovação para a melhoria dos resultados, a melhoria da comunicação e da qualidade e resultados dos trabalhos realizados. Como pontos fracos estão à falta de planejamento administrativo e financeiro e a inexistência de indicadores para medir o impacto.

Quadro 7 - Critério Resultados de GC: proposição de melhorias

\begin{tabular}{|l|l|c|c|}
\hline \multicolumn{5}{|c|}{ CRITÉRIO 7.0 - RESULTADOS DE GC } & Responsáveis & Prazo \\
\hline Editora & \multicolumn{1}{|c|}{ Propostas } & \\
Todas & $\begin{array}{l}\text { Criar plano de gestão do conhecimento que permita criar } \\
\text { indicadores para aumentar a eficiência, a qualidade, a } \\
\text { efetividade social, bem como a identificação, a criação, o } \\
\text { armazenamento, o compartilhamento e a aplicação do }\end{array}$ & $\begin{array}{c}\text { Direção e } \\
\text { chefias }\end{array}$ & 6 meses \\
\hline
\end{tabular}

Perspectivas em Gestão \& Conhecimento, João Pessoa, v. 10, n. 2, p. 120-142, maio/ago. 2020. 
conhecimento

Fonte: Elaborado pelas autoras (2018)

O Quadro 8 apresenta as propostas de melhorias para o critério 7.0.

Tendo em vista que os respondentes das três Editoras não identificaram indicadores para medição da aplicação da GC, a proposta do Quadro 7 refere-se à criação de um plano de GC nas três Editoras pesquisadas.

\section{CONSIDERAÇÕES FINAIS}

Neste estudo, procurou-se elucidar, diante do objetivo proposto, as oportunidades de melhorias em relação à Gestão da Informação e do Conhecimento em três editoras pesquisadas.

O critério Tecnologia foi o primeiro colocado nas três editoras. Aprendizagem e Inovação apareceram em 2 ㅇ lugar nas Editoras A e B. Na Editora C, a dimensão Pessoas ficou em 2ㅇ lugar, que coincidiu em terceiro também nas Editoras A e B. Na Editora C apareceu o 5.0 Processos de Conhecimento. Este foi o 40 colocado da Editora B e 5ㅇ da Editora A. O 4ㅇ lugar nas Editoras $\mathrm{A}$ e $\mathrm{C}$ foram o mesmo: Liderança, que representou a quinta posição na Editora $\mathrm{B}$, empatada com Processos, também em 5o lugar na Editora C. O sexto colocado veio dividido entre Processos (Editora A), Aprendizagem e Inovação (Editora C) e Resultados de GC (Editora B). Resultado de GC é o último colocado também nas Editoras A e C.

Em relação à análise dos pontos fortes e pontos fracos, utilizou-se o procedimento estabelecido por Bardin para a análise de conteúdo: pré-análise, exploração do material e tratamento dos resultados - a inferência e a interpretação. Alguns pontos fortes e fracos foram coincidentes com as respostas do questionário. Em outros casos, os respondentes utilizaram o espaço aberto para citar questões mais pontuais de seus locais de trabalho, não previstas nas proposições do modelo escolhido.

Após a contemplação dos objetivos específicos "a" e "b", passou-se para a apresentação do grau de maturidade em gestão do conhecimento das três Editoras pesquisadas. A Editora A atingiu 141 pontos e a Editora C, 131 pontos, ambas no nível "Introdução/expansão", ou seja, ocorrem práticas de gestão do conhecimento em algumas áreas. Na Editora A a pontuação atingiu 110, o que resulta no nível "Iniciação", quando começa a reconhecer a necessidade de gerenciar o conhecimento.

Destacou-se, no entanto, que apesar de ter obtido uma pontuação menor em relação às outras duas Editoras, os pontos fortes destacados fazem crer que a Editora A também está no nível Introdução, pois há algumas iniciativas de GC colocadas em prática. Possivelmente o fato de estar passando por uma reestruturação tenha tornado os participantes da pesquisa mais críticos na avaliação dos questionamentos, bem como algumas incertezas em relação aos processos.

Para finalizar a análise dos dados foram apresentadas propostas de melhorias baseadas na literatura, nas pontuações do questionário e nos pontos fortes e pontos fracos apontados pelos respondentes da pesquisa. As propostas envolvem toda a equipe das Editoras e são de baixa complexidade, variando de 1 a 8 meses para sua aplicação. São de baixo custo ou custo zero, envolvendo principalmente a mudança da visão da equipe, das chefias e da direção, passando a ser mais voltadas para a gestão do conhecimento.

Com relação à aplicação dos questionários, ressalta-se primeiramente a dificuldade em alcançar o número de respostas, o que ocorreu após diversos contatos presenciais ou por

Perspectivas em Gestão \& Conhecimento, João Pessoa, v. 10, n. 2, p. 120-142, maio/ago. 2020. 
correio eletrônico. Coloca-se também a dificuldade apresentada pelos participantes com as terminologias utilizadas nas 42 proposições do instrumento de coleta de dados, exigindo pesquisas em mecanismos de buscas concomitantemente ao preenchimento do formulário eletrônico.

O diagnóstico apresentado neste estudo vem consolidar a interdisciplinaridade da Ciência da Informação, tendo a Administração como um de seus pilares para solução de problemas, especialmente na área de gestão de organizações.

Tal estudo servirá de subsídio para a elaboração de um plano de gestão do conhecimento para as três editoras pesquisadas, o qual poderá contribuir de maneira decisiva para a aplicação de um processo de GC de forma sustentada, além de propiciar o Aprendizado Organizacional, que contribuirá para os processos por meio da renovação continuada do conhecimento.

Como recomendação, com objetivo de propor continuidade da pesquisa desenvolvida e preencher lacunas de conhecimento, sugere-se a realização dos seguintes estudos: a) Aplicar o modelo em outras Unidades de Informação das Universidades pesquisadas, com a finalidade de comparação e possível generalização; b) Pesquisar as relações existentes entre cada critério pesquisado e a Gestão do Conhecimento; c) Propor um instrumento de gestão do conhecimento que contemple as sete dimensões da APO, mas que seja mais acessível para quem desconhece as terminologias.

\section{REFERÊNCIAS}

ARAÚJO, C. A. A. Fundamentos da ciência da informação: correntes teóricas e o conhecimento da informação. Perspectivas em Gestão \& Conhecimento, João Pessoa, v. 4, n. 1, p. 57-79, jan./jun., $2014 . \quad$ Disponível em: http://www.periodicos.ufpb.br/ojs/index.php/pgc/article/view/19120/1082714205. Acesso em: 10 ago. 2017.

ASIAN PRODUCTIVITY ORGANIZATION (APO). Knowledge management: facilitator's guide. 2009. Disponível em: http://www.apo-tokyo.org/publications/wpcontent/uploads/sites/5/Knowledge

ManagementFacilitatorsGuide-Complete-version.pdf. Acesso em: 12 set. 2017.

BARDIN, L. Análise de conteúdo. São Paulo: Edições 70, 2016. ISBN 978-85-62938-04-7.1.

BATISTA, F. F. Modelo de gestão do conhecimento para a administração pública brasileira: como implementar a gestão do conhecimento para produzir resultados em benefício do cidadão. Brasília: Ipea, 2012.

BRASIL. Constituição. Constituição da República Federativa do Brasil. Brasília, DF: Senado Federal: Centro Gráfico, 1988. 292 p.

BUFREM, L. S. Editoras universitárias no Brasil: uma crítica para a reformulação da prática. 2. ed. rev. e atual. São Paulo: Editora da USP, 2015. ISBN 978-8531415234.

CHAN, K. H.; CHU, S. K.W.; WU, W. W. Y. Exploring the correlation between knowledge management maturity and intellectual capital efficiency in mainland chinese listed companies. Journal of Information and Knowledge Management, v. 11. art. no. 1250017, 2012. ISSN

Perspectivas em Gestão \& Conhecimento, João Pessoa, v. 10, n. 2, p. 120-142, maio/ago. 2020. 
1793-6926 versão online. DOI 10.1142/S0219649212500177.

CHAWLA, D.; JOSHI, H. Knowledge management initiatives in indian public and private sector organizations. Journal of Knowledge Management, v. 14, n. 6, p. 811-827, 2010. ISSN 13673270. DOI 10.1108/13673271011084871.

CHONG, C. W.; CHOY, C. S.; WONG, K. Y. Is the malaysian telecommunication industry ready for knowledge management implementation? Journal of Knowledge Management, v. 13, n. 1, p. 69-87, 2009. ISSN 1367-3270. DOI 10.1108/13673270910931170. Disponível em: https://www.researchgate.net/profile/Siong-

Choy Chong/publication/220363504 Is the Malaysian telecommunication industry ready $f$ or knowledge management implementation/links/54d482a40cf2970e4e634b01/Is-the-

Malaysian-telecommunication-industry-ready-for-knowledge-managementimplementation.pdf. Acesso em: 12 out. 2017.

COSTA, L. F.; GOMES, J. O.; DUARTE, E. N.; VALENTIM, M. L. P. Reflexões sobre o estado da arte da gestão da informação e do conhecimento por Emeide Nóbrega Duarte. Perspectivas em Gestão \& Conhecimento, v. $\quad 8$, n. $\quad 2$, p. 194-204, 2018. DOI: $10.21714 / 2236-$ 417X2018v8n2. Acesso em: 03 jul. 2020.

CUNHA, M. B. da; AMARAL, S. A. do A.; DANTAS, E. B. Manual de estudo de usuários da informação. São Paulo: Atlas, 2015. ISBN 978-85-224-9877-2.

DALKIR, K. Knowledge management in theory and practice. Boston: Elsevier, 2005. ISBN 07506-7864-X.

DAVILA, G. A. et al. O ciclo de gestão do conhecimento na prática: um estudo nos núcleos empresariais catarinenses. Int. J. Knowl. Eng. Manage., Florianópolis, v. 3, n. 7, p. 43-64, fev. 2015. ISSN 2316-6517 Disponível em: http://incubadora.periodicos.ufsc.br/index.php/IJKEM/article/view/2792/377. Acesso em: 15 mar. 2015.

FREIRE, P. de S. et al. Ferramentas de avaliação de Gestão do Conhecimento: Um estudo bibliométrico. International Journal of Knowledge Engineering and Management (IJKEM), v. 2 n. 3, p. 15-38, 2013. ISSN 2316-6517. Disponível em: http://incubadora.periodicos.ufsc.br/index.php/IJKEM/article/view/2322/2655. Acesso em: 25 maio 2017.

HERRERA, C. G. N. El liderazgo em la gestión del conocimento. 2010. Disponível em: http://goo.gl/fj7gEk. Acesso em: 3 ago. 2016.

KITCHENHAM, B. Procedures for performing systematic reviews, Joint Technical Report Software Engineering Group, Department of Computer Science, Keele University, United King and Empirical Software Engineering, National ICT Australia Ltd., Australia, 2004.

KRAEMER, R. et al. Maturidade de gestão do conhecimento: uma revisão sistemática da literatura para apoiar o desenvolvimento de novos modelos de avaliação. Perspectivas em Gestão \& Conhecimento, v. 7, n. N. Especial, p. 66-79, 2017. ISSN 2236-417X. Disponível em: http://www.periodicos.ufpb.br/ojs/index.php/pgc/article/view/32946/17302. Acesso em: 3 ago. 2016.

Perspectivas em Gestão \& Conhecimento, João Pessoa, v. 10, n. 2, p. 120-142, maio/ago. 2020. 
KRUGER, C. J.; SNYMAN, M. M. M. Guidelines for assessing the knowledge management maturity of organizations. South African Journal of Information Management, v. 9. n. 3, 2007. Disponível em:

http://citeseerx.ist.psu.edu/viewdoc/download?doi=10.1.1.472.6131\&rep=rep1\&type=pdf. Acesso em: 20 ago. 2017.

LEE, C. S.; WONG, K.Y. Knowledge management performance measurement in micro-, small-, and medium-sized enterprises: an exploratory study. Business Information Review, v. 32, p. 204-211, 2015. DOI 10.1177/0266382115615262.

MAIA, C. S. R. Casa de ferreiro, espeto de pau: a gestão do conhecimento em empresas produtoras do conhecimento. In: TERRA, J. C. C. (Org.). Gestão do conhecimento e e-learning na prática: 39 casos práticos. Rio de Janeiro: Negócio Editora, 2003. ISBN 9788575890158

MATTERA, T. C. Gestão do conhecimento na prática. In: SOUTO, L. F. (Org.). Gestão da informação e do conhecimento: práticas e reflexões. Rio de Janeiro: Interciência, 2014. ISBN 978-8571933354

NONAKA, I.; TAKEUCHI, H. Criação de conhecimento na empresa: como as empresas japonesas geram a dinâmica da inovação. Rio de Janeiro: Campus, 1997. ISBN 9788535201772.

NONAKA, I.; VON KROGH, G. Perspective-tacit knowledge, and knowledge conversion: controversy and advancement in organizational knowledge creation theory. Organization Science, v. 20, n. 3, 2009. ISSN 1526-5455 versão online. Disponível em: https://pubsonline.informs.org/doi/abs/10.1287/orsc.1080.0412. Acesso em: 07 mar. 2018.

OSTERWALDER, A.; PIGNEUR, Y. Business Model Generation: inovação em modelos de negócios: um manual para visionários, inovadores e revolucionários. Alta Books, 2011. ISBN 978-8576085508.

PEE, L. G.; KANKANHALLI, A. A model of organisational knowledge management maturity based on people, process, and technology. Journal of Information and Knowledge Management, v. 8. p. 79-99, 2009. ISSN 1560-683X. DOI 10.1142/S0219649209002270. Disponível em: https://www.researchgate.net/publication/263803353 A Model of Organisational Knowled ge Management Maturity Based on People Process and Technology. Acesso em: 07 mar. 2018.

PROBST, G.; RAUB, S.; ROMHARDT, K. Gestão do conhecimento: os elementos construtivos do sucesso. Porto Alegre: Bookman, 2002. ISBN 9788577801350.

SANTOS, C. D.; VALENTIM, M. L. P. As interconexões entre a gestão da informação e a gestão do conhecimento para o gerenciamento dos fluxos informacionais. Perspectivas em Gestão \& Conhecimento, v. 4, n. 2, p. 19-33, 2014 . Disponível em: http://hdl.handle.net/20.500.11959/brapci/49728. Acesso em: 03 jun. 2020.

SIEMENS (2004). Knowledge management maturity model (KMMM). Disponível em: http://www.kmmm.org/objects/KMMM WC on IC2001 2001-01-18.pdf. Acesso em: 20 mar. 2018.

Perspectivas em Gestão \& Conhecimento, João Pessoa, v. 10, n. 2, p. 120-142, maio/ago. 2020. 
SPENDER, J. C. Gerenciando sistemas de conhecimento. In: FLEURY M. T. L.; OLIVEIRA JR., M. de M. (org.). Gestão estratégica do conhecimento: integrando aprendizagem, conhecimento e competências. São Paulo: Atlas, 2001. ISBN 978-8522429097.

UFPR, Editora da. Institucional. 2018. Disponível em: http://www.editora.ufpr.br/. Acesso em: 03 nov. 2018.

UFRGS, Editora da. Editora. 2018. Disponível em: http://www.ufrgs.br/. Acesso em: 03 nov. 2018.

UFSC, Editora da. Editora. 2018. Disponível em: http://editora.ufsc.br/. Acesso em: 03 nov. 2018.

URIARTE, F. Introduction to Knowledge Management. Asian Foundation: Jakarta, 2008.

YIN, R. K. Case study research: design and methods. 5. ed. Thousand Oaks, CA: Sage, 1990. ISBN 978-1-4522-4256-9.

YOUNG, R. Knowledge management: tools and techniques manual. Asian productivity organization. Tóquio, 2010. Disponível em: http://www.apo-tokyo.org/publications/wpcontent/uploads/sites/5/ind-43-km tt-2010.pdf. Acesso em: 31 jul. 2016.

Artigo recebido em 23/09/2019 e aceito para publicação em 19/05/2020 